\title{
Health Monitoring System using Wireless Body Area Network and ANDROID supported PDA
}

\author{
Mahadeo D. Kokate, PhD \\ Principal \& Professor \\ SNJB's K.B.J COE \\ Neminagar, Chandwad
}

\author{
Ankush S. Joshi \\ M.E. E\&TC \\ SNJB's K.B.J COE \\ Neminagar, Chandwad
}

\author{
Vishal A. Wankhede, PhD \\ HOD of E\&TC Dept. \\ SNJB's K.B.J COE \\ Neminagar, Chandwad
}

\begin{abstract}
Late remote sensor systems have empowered the configuration of minimal effort, clever, small, and lightweight therapeutic sensor hubs that can be deliberately put on human body, make a remote body region system called Wireless Body Area Network (WBAN) to screen different physiological indispensable signs for a drawn out stretch of time and giving ongoing input to the client and medicinal staff. WBANs guarantee to revolutionize wellbeing observing. In this paper, medicinal sensors were utilized to gather physiological information from patients and transmit it to personal digital assistant (PDA) utilizing bluetooth standard and to restorative server utilizing $3 \mathrm{G}$ correspondences. In this paper, we present new trends, various innovations such as we are using bluetooth technology which is not used earlier. also we are going to develop android application for PDA in order to capture the data from sensors as well as it can provide facility of storing \& sharing the patients results to doctors, physicians etc. through internet.
\end{abstract}

\section{General Terms}

Human health monitoring, wireless sensor network, 2G/3G wireless network

\section{Keywords}

Bluetooth data transfer, android application, wireless body area network

\section{INTRODUCTION}

Remote Sensor Systems (WSNs) with clever sensor hubs are getting to be critical empowering innovation for wide range applications. Late innovation progresses in coordination and scaling down of physical sensors, microchips, and radio interfaces on a solitary chip, have empowered another era of remote sensor net-works reasonable for some applications[1]. For instance, they can be utilized for crisis reaction, modern computerization, military observation, seismic, natural checking, agrarian applications, and human services observing[2]. A remote sensor system comprises of numerous hubs furnished with a detecting unit, memory, microcontroller (chip), remote correspondence interface and force source constituting of a multi-bounce system, where hubs in the same region can speak with each other with steering duties. As opposed to the customary sensor organizes that are precisely arranged and sent in the foreordained positions, WSNs can be conveyed in an impromptu way which make them hearty, adaptation to non-critical failure, and increment in spatial scope. They can significantly be utilized to screen and track states of patients in both urban communities and rustic ranges utilizing an intranet or web in this way lessening the anxiety of social insurance suppliers, kill restorative mistakes, decrease workload and increment proficiency of doctor's facility staff, diminish long haul expense of medicinal services benefits, and enhance the solace of the patients[3]. These mistakes happen because of absence of right and finish data at the area at the time it is required, bringing about wrong analysis and medication communication issues[4]. Sensor hubs can be deliberately put on the human body make a bunch that is called remote body territory system (WBAN) that can be utilized to gather patient's fundamental signs[5]. It is important that sensor hubs are being worked by batteries, their energy utilization amid transmission must be insignificant for effective and solid information transmission amongst WBAN and individual server. Utilizing sensor hubs with correspondence advancements, for example, cellular telephones i.e. PDA, General Parcel Radio Administration (GPRS), 3G, and the web, the sensor system can keep patient, parental figures, and specialist educated while likewise setting up patterns and identifying varieties in well being. In this paper, we propose a systems administration arrangement in which a Therapeutic Super Sensor (MSS) is utilized to gather numerous physiological signs detected by each of the body sensors in WBAN and forward them to the individual server. An Insightful Individual Computerized Associate (IPDA) is utilized as an individual server.

\section{PROPOSED SYSTEM}

Sensor hubs can sense, test, and process one or more physiological signs. For instance, an electrocardiography (EKG) sensor can be utilized for checking heart movement, a pulse sensor can be utilized for observing circulatory strain, a breathing sensor for checking breath, an electromyogram (EMG) sensor for checking muscle action, and an electroenphalogram (EEG) sensor for observing mind electrical touch base for every sensor. In our outline, a modern sensor is coordinated into the WBAN called Therapeutic Super Sensor (MSS). This sensor has more memory, preparing and correspondence capacities than other sensor hubs. MSS utilizes a radio recurrence to speak with other body sensors and ZigBee is utilized as a communication convention to speak with the Individual Server. In this configuration, we considered Bluetooth innovations. In the event of Bluetooth particular, it supports greatest of seven dynamic slaves (i.e. sensors to be controlled by one expert, individual server). Sensor is a detecting chip to sense physiological information from the patient's body. Microcontroller is utilized to perform neighbourhood information preparing, for example, information pressure and it additionally controls the usefulness of different segments in the sensor hub. Memory is utilized to store detected information transiently. Radio Handset is in charge of communication amongst hubs and to send/get detected physiological information remotely. Sensor hubs are fuel by batteries with a lifetime of a while[18]. 


\subsection{Physiological signs}

There are diverse physiological signs that are normally transmitted between the sensor hubs and patient server. High information rate implies basic signs that should be exchange quick with high unwavering quality while low inertness implies time postponement to the reaction of transmission of basic flags and ought to be however much as could reasonably be expected be short. From Table 2 underneath, each of the physiological signs is given need weight. It demonstrates the request in which the physiological signs will transmit from IPDA to the medicinal server by means of $3 \mathrm{G}$ interchanges for further examination and analysis by the therapeutic staff.

Physiological sign that is designated with need 1 has the most noteworthy need over other information and will be permitted to transmit first and the fundamental sign ought to be transmitted immediately. It implies the current state of the patient is basic and he/she needs quick consideration of the restorative staff while physiological sign with high information rate and high idleness implies the sign is not basic. It will pack as indicated by a given proportion and put away in the nearby memory of the IPDA for later transmission after physiological signs with higher need i.e. need 1 , need 2 have been permitted to transmit first. From what has been talked about above, convenient access to the patient's restorative data is imperative for giving right treatment and enhancing the general wellbeing of the patient's consideration. Need booking strategy not just lessens the transmission delay for basic physiological signs, additionally diminishes activity clog. The aggregate number of information sent decreased through information pressure strategy. In this manner, the transfer speed use is enhanced along these lines, lessens all out transmission time. In any case, IPDA is utilizing battery for its operation and high measure of vitality is devoured amid transmission [19]. This technique diminishes vitality devoured by the IPDA amid transmission since just the basic fundamental signs will transmit first while less basic signs are put away and transmit later.

\subsection{Medical Server for health care monitoring (MSHM)}

The third level is called Medical Server for health care monitoring (MSHM). It gets information from the individual server, is the foundation of the whole design. It is arranged at restorative focuses where therapeutic administrations are given. It is savvy since it is fit for learning quiet particular edges and gains from past treatment records of a patient[20].
MSHM keeps electronic restorative records (EMRs) of enlisted patients, which are available by various medicinal staff, including general professionals, experts and specialists from their workplaces in the doctor's facility over the web. The current situation with the patient can be seen by the therapeutic staff. MSHM is in charge of client verification, tolerating information from individual server, configuration and addition the got information into relating EMRs, dissect the information designs. The patient's doctor can get to the information and its examples from his/her office by means of the intranet/web and inspect it to guarantee the patient is inside expected wellbeing measurements. In the event that got information is out of reach (i.e. deviation from edge) or perceive genuine wellbeing irregularities condition, restorative staff in the crisis unit can be told to take essential activities. Nonetheless, if the patient is in the remote range, the expert specialist will watch the physiological information of the patient analyze it, recommend the vital treatment and medications for the patient. This data will sent back to the specialist in the remote healing centre through the web. The MSHM likewise gives criticism directions to the patient, for example, doctor's endorsed works out.

Table 1. Physiological signal characteristics

\begin{tabular}{|c|c|c|c|}
\hline Physiological signs & $\begin{array}{c}\text { Data } \\
\text { rate(kbps) }\end{array}$ & $\begin{array}{c}\text { Parameter } \\
\text { range }\end{array}$ & $\begin{array}{c}\text { Data } \\
\text { arrival } \\
\text { time(sec) }\end{array}$ \\
\hline electrocardiograph & 6 & $0.5-4 \mathrm{mv}$ & 0 \\
\hline blood flow & 0.48 & $1-300 \mathrm{ml} / \mathrm{s}$ & 0.03 \\
\hline Respiration rate & 0.23 & $\begin{array}{c}2-50 \\
\text { breaths } / \mathrm{min}\end{array}$ & 0.05 \\
\hline Oxygen saturation & 2.3 & $0.01-0.85 / \mathrm{s}$ & 0.16 \\
\hline Blood pressure & 1.2 & $\begin{array}{c}10-400 \\
\mathrm{mmHg}\end{array}$ & 0.01 \\
\hline Blood PH & 0.05 & $\begin{array}{c}6.8-7.8 \mathrm{PH} \\
\text { units }\end{array}$ & 0.25 \\
\hline Never potentials & 240 & $0.01-3 \mathrm{mv}$ & $5 \mathrm{E}-05$ \\
\hline Body temperature & 0.24 & $32-40^{\circ}$ & 5 \\
\hline
\end{tabular}

PDA is idle mode when it has no information to get from MSS or send to the therapeutic server keeping in mind the end goal to spare vitality however wake up instantly from dormant to dynamic mode to get transmitted information and store it. 


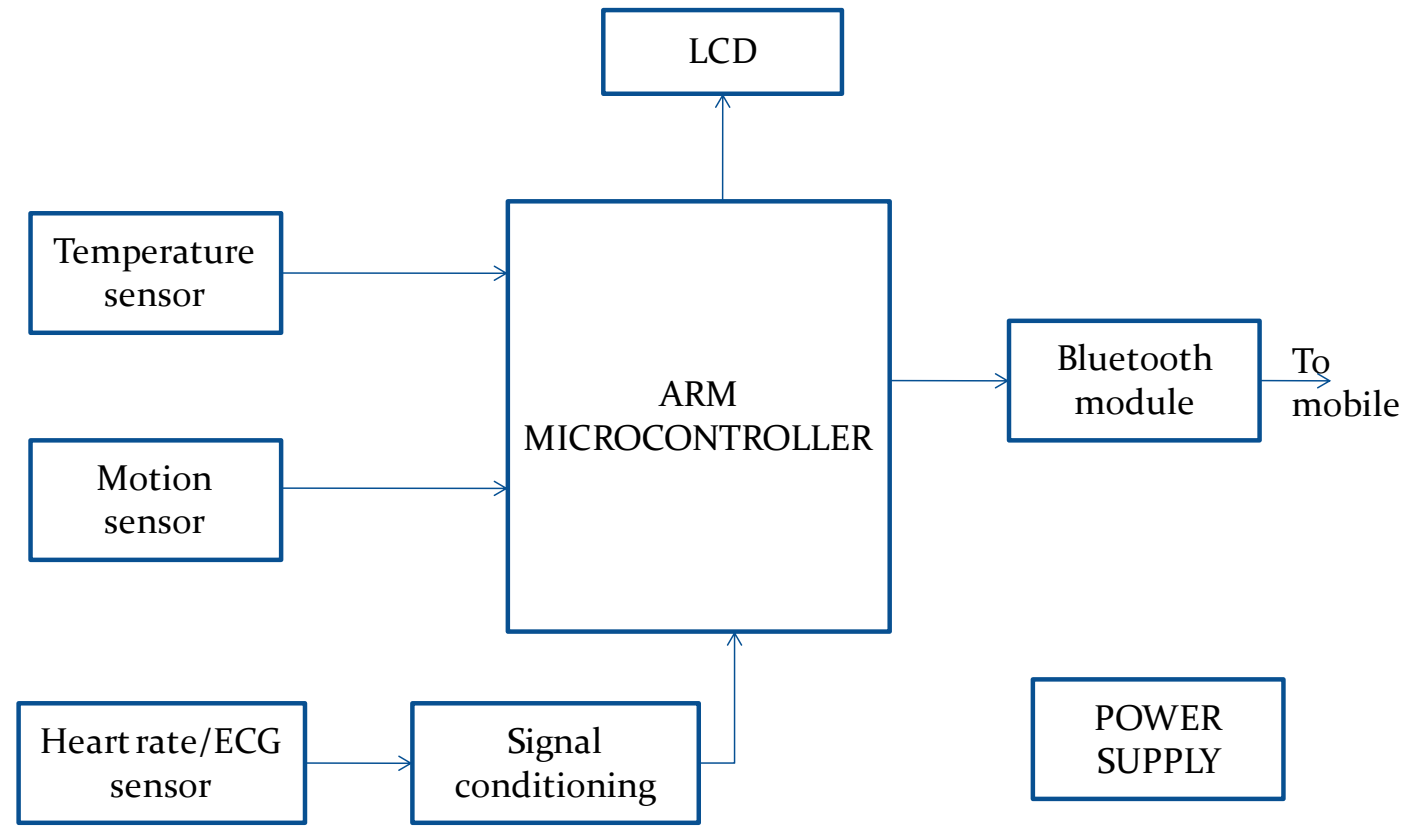

Fig 1: System architecture

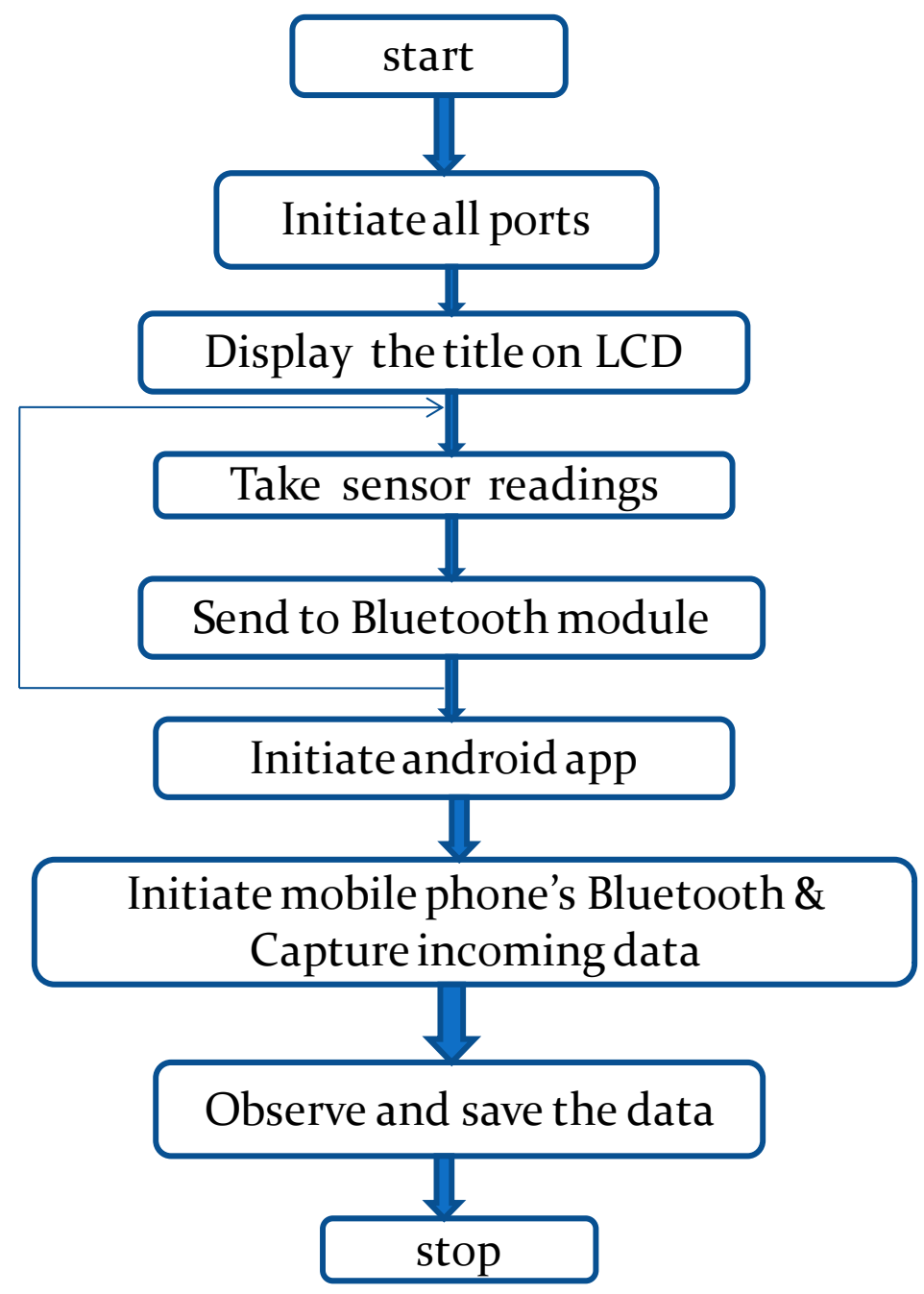

Fig 2: Flow chart 
Table 2. Priorities of signs

\begin{tabular}{|c|c|c|c|}
\hline Physiological signs & $\begin{array}{c}\text { Data } \\
\text { rate(kbps) }\end{array}$ & Latency & Priority \\
\hline electrocardiograph & High & Low & 1 \\
\hline $\begin{array}{c}\text { Heart rate, blood } \\
\text { flow }\end{array}$ & Low & Low & 2 \\
\hline $\begin{array}{c}\text { Respiration rate, } \\
\text { body temperature }\end{array}$ & Low & High & 3 \\
\hline Never potentials & High & High & 4 \\
\hline
\end{tabular}

\section{CONCLUSION}

In this paper, we portrayed the design of wearable sensors for remote human services observing framework. The strategy not just diminishes transmission postponement of physiological essential signs additionally enhances its transfer speed use. The new innovation can possibly give some advantages to patients, therapeutic staff, and society everywhere through consistent observing of different physiological fundamental signs and give ongoing input to the client and the restorative staff. We have used bluetooth technology which allow us to use PDA rather than laptop or computer \& it made us easy to carry it anywhere. Now a days, android is most popular and billions of people are accessing it that's why We have used android application to observe store as well as share patients data easily.

\section{REFERENCES}

[1] W. Wang, et al., "CEDCAP: Cluster-Based Energy-Efficient Data Collecting and Aggregation Protocol for WSNs," Research Journal of Information Technology, Vol.3,No.2,2011, pp.93-103.

[2] I. Khemapech, et al., "A Survey of Wireless Sensor Networks Technology," 6th Annual Postgraduate Symposium on the Convergence of Telecommunications, Networking and Broadcasting, Liverpool John Moores Uni-versity, Liverpool, 2005.

[3] U. Varshney, "Pervasive Healthcare: Applications, Challenges and Wireless Solutions," Communications of the Association for Information Systems, Vol. 16, No. 1, 2005 , p. 3.

[4] V. Jones, et al., "Biosignal and Context Monitoring: Distributed Multimedia Applications of Body Area Networks in Healthcare,"2008 IEEE 10th Workshop on Multimedia Signal Processing, Cairns, 8-10 October 2008, pp. 820-825.S. Vijendra, "Efficient Clustering for High Dimensional Data: Subspace Based Clustering and Density Based Clustering," Information Technology Journal, Vol. 10, No. 6, 2011, pp. 1092-1105. doi:10.3923/itj.2011.1092.1105

[5] X. Chen, et al., "Design of Sensor Node Platform for Wireless Biomedical Sensor Networks," 27th Annual International Conference of the Engineering in Medicine and Biology Society, Shanghai, 17-18 January 2006, pp. 4662-4665Brown, L. D., Hua, H., and Gao, C. 2003. A widget framework for augmented interaction in SCAPE.

[6] A. Wood, et al., "ALARM-NET: Wireless Sensor Networks for Assisted-Living and Residential Monitoring," Technical Report CS-2006-13, University of Virginia, 2006.
[7] Journal of Sensor Technology, 2011, 1, 22-28 Using Wearable Sensors for Remote Healthcare Monitoring System Ademola Philip Abidoye, Nureni Ayofe Azeez1, Ademola Olusola Adesina1, Kehinde K. Agbele, Henry O. Nyongesa, Soft Computing and Natural Language Research Group, Bellville, South Africa.

[8] Agent Based Health Monitoring of Elderly People in Indoor Environments Using Wireless Sensor Networks V.Vaidehi, M.Vardhini, H.Yogeshwaran, G. Inbasagar R.Bhargavi ,C.Sweetlin Hemalatha The 4th International Conference on Ambient Systems, Networks and Technologies (ANT 2013)

[9] Volume 5, Issue 4, 2015 ISSN: 2277 128X International Journal of Advanced Research in Computer Science and Software Engineering Applications of Wireless Sensor Networks in Medical Health Care A. M. Agarkar*, U. Manvitha, Priyal M. Tibdewal, Erum Kazi Faculty, ECE, SSGMCE, Shegaon, Maharashtra, India.

[10] W. Rosamond, et al., "Heart Disease and Stroke Statistics-2007 Update: A Report from the American Heart Association Statistics Committee and Stroke Statistics Subcommittee," Circulation, Vol.115,No.5,2007,pp.e69e171. doi:10.1161/CIRCULATIONAHA.106.179918

[11] I. Romero, et al., "Robust Beat Detector for Ambulatory Cardiac Monitoring," Annual International Conference on Engineering in Medicine and Biology Society, Minneapolis, 3-6 September 2009, pp. 950-953.

[12] World Health Organization, 2008. www.who.int

[13] RAND Corporation, "Home Health Care Could Help Sustain Health Care Systems, Study Finds," Trends in Applied Sciences Research, Vol. 6, No. 8, 2011, pp. 925926.

[14] H. T. Chu, et al., "A Ubiquitous Warning System for Asthma-Inducement," IEEE International Conference on Sensor Networks, Ubiquitous, and Trustworthy Computing, Taichung, 5-7 June 2006, pp. 186-191.

[15] A Milenkovic, et al., "Wireless Sensor Networks for Personal Health Monitoring: Issues and an Implementation," Computer Communications, Vol. 29, No. 13-14, 2006, pp. 2521-2533. doi:10.1016/j.comcom.2006.02.011

[16] A. A. Osman, "Management of Infertility within Primary Health Care Program in Sudan," Asian Journal of Scientific Research, Vol. 4, No. 2, 2011, pp. 158-164.

[17] Y. J. Zhao, et al., "A MEMS Viscometric Glucose Monitoring Device," The 13th IEE International 
Conference on Solid-State Sensors, Actuators and Microsystems, Pittsburgh, 5-9 June 2005, pp. 1816-1819.

[18] B. Lo and G. Z. Yang, "Key Technical Challenges and Current Implementations of Body Sensor Networks,"http://ubimon.doc.ic.ac.uk/bsn/public/bsn2005-Benlo.pdf
[19] G. J. Pottie and W. J. Kai, "Wireless Integrated Network Sensors," Communications of the ACM, Vol.43,No.5,2000,pp.51-58 doi:10.1145/332833.332838

[20] M. Seyyed, et al., "Fuzzy Logic Expert Systems in Hospital: A Foundation View," Journal of Applied Sciences, Vol. 11, No. 12, 2011, pp. 2106-2110. 